\title{
Motivational Interviewing as a Positive Response to High School Bullying
}

\section{(Running head: MOTIVATIONAL INTERVIEWING AND BULLYING)}

Donna Cross ${ }^{1}$, EDD; Kevin C Runions ${ }^{1,2}$, PhD; Ken A Resnicow ${ }^{3}$, PhD; Eileen F

1

\author{
Britt $^{4}$, PhD; \& Caitlin Gray ${ }^{1}$, MA
}

1. Health Promotion \& Education Research, Telethon Kids Institute, University of Western Australia

2. Touchstone, Community Child \& Adolescent Mental Health Services, Department of Health, Western Australia,

3. Health Behavior \& Health Education, School of Public Health, University of Michigan

4. Department of Psychology, University of Canterbury, New Zealand

Acknowledgements. The authors would like to acknowledge all the school staff and students who have been involved in the Beyond Bullying: Positive Change for All project, as well as the National Health and Medical Research Council (NHMRC Project 1046086).

Conflict of Interest statement: All authors declare they have no conflict of interest

\section{Corresponding Author}

Dr Kevin Runions

Telethon Kids Institute,100 Roberts Rd. Subiaco

Western Australia, 6008, Australia

Email: kevin.runions@uwa.edu.au

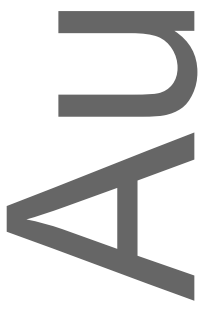

This is the author manuscript accepted for publication and has undergone full peer review but has not been through the copyediting, typesetting, pagination and proofreading process, which may lead to differences between this version and the Version of Record. Please cite this article as doi: 10.1002/pits.21120.

This article is protected by copyright. All rights reserved. 


\begin{abstract}
Intervention approaches to bullying are largely preventive in nature, and even these have been shown to be ineffective, if not iatrogenic, with adolescents. Responses to bullying are limited to traditional punitive approaches or "no-blame" approaches aiming to restore the relationship between the targeted students. Neither of these approaches may effectively engage the perpetrator of bullying at a motivational level, and we propose motivational interviewing (MI) as a means of promoting meaningful behavioral change amongst youth who bully. We provide a narrative review MI and map its core features onto the extant literature on self-reported motivations for bullying, highlighting the ways that MI fits with
\end{abstract} bullying and could serve as a potent solution that could be deployed by school psychologists and other student support staff members. Qualitative preliminary feedback and initial competency in MI from trained practitioners are presented as preliminary data from a clusterrandomized control trial documenting school staff perspectives on the integration of MI into their approach to bullying are presented, with recommendations for integrating MI into school settings.

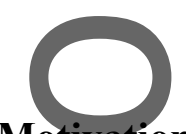

\title{
Motivational interviewing as a Positive Response to High School Bullying
}

Peer bullying amongst young people is a stubborn social problem. Despite media and public attention to the issue, as well as substantial research, bullying remains a concern for both students and schools. The most effective approach currently being used to address school-based bullying involves whole-school interventions that include school, classroom, home, and student-level strategies (Smith, Schneider, Smith, \& Ananiadou, 2004; Ttofi \& Farrington, 2011). While these programs have had some success at reducing reported levels of bullying, the effect sizes are - at best -- relatively small (Ttofi \& Farrington, 2011). 
Indeed, a meta-analysis suggested that preventive "anti-bullying" interventions may be counterproductive amongst adolescent school populations, leading to increases in bullying (Yeager et al., 2015). Perhaps the chief challenge has been in addressing bullying behavior at the source: the ehildren and young people who engage in repeated or severe bullying. This article provides a review of the challenges in reactive approaches to bullying and their shortcomings in addressing adolescent bullying behavior, and suggests an innovative application of an established intervention approach - motivational interviewing- to support young people in discontinuing their bullying behavior.

Current interventions have failed to address the chief challenge in working with young people involved in serious bullying: they may be entirely unmotivated to stop bullying. This paperargues that in failing to account for the social goals and motivations underlying bullying incidents, schools do not provide a nuanced intervention strategy. Further, the use of $\mathrm{MI}$ is advocated as a first step in any reactive approach to help youth find non-aggressive ways to achieve their social goals. The paper provides a brief overview of the nature of problems for which MI has proven effective, and by examining the theoretical and therapeutic aspects of MI, demonstrates that these present a promising avenue for working with youth who bully others. Finally, the paper discusses how MI can be integrated with other intervention methods to provide a tailored approach to addressing bullying perpetration.

\section{Bullying: The Scope of the Problem}

The most accepted definition of bullying refers to intentional acts of aggression that occur repeatedly, within a relationship marked by a power imbalance wherein the victim cannot easily defend him/herself (Olweus, 1993). This excludes conflict between more-orless equal peers, one-off attacks or fights, and mutually enjoyable jokes and teasing between friends (Berger, 2007). Bullying can take many forms, including physical violence verbal aggression (teasing, threatening, or belittling a victim), or social or relational aggression that 
aims to harm the victim's social status and wellbeing (e.g., spreading rumours).

Cyberbullying occurs when victims are targeted by electronic means. Regardless of its form, bullying behavior can be harmful to the wellbeing of all involved. Bullying victimisation is a well-established risk factor for a range of mental health problems, including eating disorders, low self-esteem, poor relationships and loneliness, deliberate self-harm, and suicidal ideation and attempts (Hemphill et al., 2011; Kim, Catalano, Haggerty, \& Abbott, 2011; Lester, Cross, Dooley, \& Shaw, 2013; Ttofi, Farrington, Loesel, \& Loeber, 2011; Van Geel, Vedder, \& Tanilon, 2014).

Bullying perpetrators are also at risk for mental health problems such as internalizing problems (anxiety, depression and psychosomatic problems), an increased risk of suicide, other forms of violence, and risk-taking behaviors such as binge drinking and marijuana use (Delfabbro et a1., 2006; Hemphill et al., 2011; Moore et al., 2014; Roland, 2002). A subset of perpetrators are also victims of bullying, and this group may experience the highest levels of social and emotional harm (e.g. Ttofi, Farrington, Lösel, Özdemir, \& Stattin, 2011). Finally, bystanders to bullying report increased symptoms of distress, anxiety and depression; particularly if they themselves have previously been bullied (Werth, Nickerson, Aloe, \& Swearer, 2015). Intervening to address and prevent bullying is therefore in the best interests of all involved youth; however there is little evidence that current interventions are effective.

\section{School Responses to Bullying}

What should schools do when bullying occurs? Most bullying interventions are preventive in nature and address core social processes and psychoeducation relevant to improving peer relationships. Less is known about how schools can effectively respond to bullying once it has occurred. There is little evidence on the relative efficacy of different systematic approaches to dealing with the problem once it has arisen. Recent critical reviews of reactive school-based approaches to bullying such as Rigby (2014) have contrasted 
traditional disciplinary responses to bullying perpetration, which treat bullying as a moral problem warranting a punitive response (e.g. suspension from school), with approaches derived from a counselling model, such as restorative justice, the support group method, and the method of shared concern. These counselling models tend to engage the perpetrator(s) in a reparative process that aims to resolve the fundamental social problems that are hypothesized to have given rise to the bullying. Counselling approaches depend on engaging the bullying perpetrator into a feeling of responsibility for the impact of their behavior (Rigby, 2014). The empirical evidence examining the efficacy of such approaches is scant, but that which exists suggests that reparative approaches show greater efficacy than disciplinary approaches to reduce bullying (Rigby, 2014).

However, almost no randomized control trials studies have tested the efficacy of one responsive approach to reducing bullying among students over another. The only study, to our knowledge, that has tested reactive interventions with random assignment to condition is the ongoing KiVastudy in Finland (e.g. Garandeau, Poskiparta, \& Salmivalli, 2014). KiVa schools were randomly assigned to use reactive approaches that involved either directly holding the bullying student responsible for what had transpired with this student being asked to cease the behavior immediately or in the other condition, a concern for the targeted student is shared with the perpetrator of the bullying, without blaming the perpetrator directly. This study found that the two approaches had equivalent outcomes in primary school, but by secondary school, the approach that openly holds the perpetrator to account was significantly more effective in stopping the bullying, though the effect size was small (Garandeau, Lee, \&

Salmivalli, 2014).

What Might Make a Student Stop Bullying?

Often, the reason(s) a young person stops bullying will be individually determined. For some students, highlighting the harm they are doing while avoiding shame may work; for 
another, their personal responsibility for their behavior may need to be evoked. For those perpetrating bullying, self-reported intention to stop that behavior is predicted by the extent to which their empathy for the targeted student is aroused, but also when the behavior was clearly condemned (but not when the bullying student was personally blamed; Garandeau, Vartio, Poskiparta, and Salmivalli (2016)). These two processes - re-affirming the moral violation that bullying entails and highlighting the harm that may arise - may also work synergistically to promote change (Garandeau et al., 2016) via moral re-engagement.

Activating the moral engagement required to stop bullying is a formidable challenge; however, it maybe a necessary first step. Reparation approaches are predicated on the willingness of all parties - including the perpetrator - to engage in meaningful reparation. As Rigby (2014) has noted, this approach is more likely to be effective for students who have been experiencing conflict, and not bullying per se. That is, there is no power imbalance involved. The support-group method (aka., the 'no blame' approach) seeks to instill a sense of responsibility amongst perpetrators to "make the bullied pupil feel happy and safe" (Thompson \& Smith, 2012, p. 113, p. 113), but the safety and happiness of their target may not be a realizable goal if the perpetrators believes the target provoked or deserved the incident. Similarly, the method of shared concern was developed to evoke a sense of responsibility for making amends, but the method is hampered when bullying perpetrators are not motivated to feel regret or change their behavior.

Thus, a key impediment to stopping bullying behavior, and the success of counselling interventions for bullying, is likely to be the degree of motivation for change amongst bullying perpetrators. An approach is needed that increases the bullying perpetrator's motivation to stop. This is where MI may be of value.

\section{What is Motivational interviewing?}


Miller and Rollnick (2012) describe MI as an approach for guiding conversations about behavior change. More than a set of techniques, MI brings together a set of values, processes and skills to assist individuals in resolving ambivalence and deepening motivation to pursue changes that are meaningful to them. The values of MI create a 'way of being' with people, sometimes referred to as the 'sprit' of MI. These values comprise:

- Partnership. Using MI as a collaborative conversation between two equals.

- Acceptance. Recognizing and valuing the absolute worth of the young person and honoring their autonomy.

- Compassion. Practicing MI with the best interests of the young person at heart.

- Evocation. Recognizing that the potential for change and growth already lies within the individual, and the task of the practitioner is to guide the conversation to evoke and strengthen this potential.

MI also involves four fundamental processes, with each building the foundation for the subsequent process. These comprise: engagement - establishing a sound relationship is essential for MI to occur; focusing - where the young person and the practitioner work together to focus on the area(s) of potential change; evoking - the practitioner works to draw out and strengthen motivations for the young person wanting things to be different and desire for change, and planning - when the young person is ready to change, they work with the practitioner to plan how change might occur.

These four processes are facilitated by the strategic use of micro-counselling skills of reflections, open questions, affirmations, and summarizing. Reflective listening is a core skill and is used to convey understanding and encourage the young person to talk more, and avoids the question-answer trap which can make the young person the passive responder. In MI 
questions are mostly open questions, which are used to encourage the young person to talk more, or are evocative open questions which elicit motivations for change. Affirmations are used to express positive regard and caring, strengthen engagement, decrease defensiveness, and strengthen the young person's sense of self-efficacy and confidence in their ability to change. Summaries, as well as providing the opportunity to clarify the shared understanding that is developing between the young person and the practitioner, allow the practitioner to repeat the motivations for change which may have been expressed by the young person, so that they hear these motivations again. In addition to these micro-counselling skills, a way of providing information, feedback or advice has been developed so that this process remains consistent with the spirit of MI, maintaining a collaborative, respectful process.

Motivational interviewing has a strong empirical evidence base. The method has been cited in over 25,000 articles and more than 200 clinical trials (Miller \& Rollnick, 2012). There is good evidence for the efficacy of MI with alcohol and other substance abuse and dependence problems, as well as increasing evidence for its efficacy with a range of other problems, as diverse as health behavior change, and offending. There is also growing evidence of its efficacy with adolescents as well as adults (Sarah J Erickson, Melissa Gerstle, \& Sarah W Feldstein, 2005; Naar-King \& Suarez, 2011). Additionally, there has been increasing interest in the use of MI within schools (Blom-Hoffman \& Rose, 2007; Frey et al., 2011; Lee, Frey, Herman, \& Reinke, 2014; Strait, McQuillin, Smith, \& Englund, 2012; Strait, McQuillin, Terry, \& Smith, 2014). There are two published books focused on MI in schools (Herman, Reinke, Frey, \& Shepard, 2013; McNamara, 2009), and research studies providing evidence to support the use of MI within schools for a range of behaviors from health and mental health problems, including substance abuse, academic performance and career development for youth with disabilities (Atkinson \& Woods, 2003; Reich, Sharp, \& Berman, 
2015; Sheftel, Lindstrom, \& McWhirter, 2014; Strait, Smith, et al., 2012; Terry, Strait, McQuillin, \& Smith, 2014).

Finally, MI appears to be a promising method for addressing violence and aggression. Positive results have been reported in reducing violence in domestic and romantic contexts (Kistenmacher \& Weiss, 2008; Musser, Semiatin, Taft, \& Murphy, 2008; Woodin \& O’Leary, 2010)-Further, a MI-informed brief intervention was delivered by emergency department (ED) nurses in a Level 1 trauma center in Flint, Michigan, aimed at adolescents (aged 14-18 years) presenting to hospital ED for alcohol and aggression-related injury and medical illness (Cunningham et al., 2009). This intervention, averaging 37 minutes in duration, resulted in statistically significant improvement in attitudes toward violence and self-efficacy to avoiding fighting (Cunningham et al., 2009) and reductions in severe peer aggression up to 12 months later (Cunningham et al., 2012). These studies suggest that MI may be effective in addressing other modes of aggression including school bullying.

\section{The Potential for MI to Help Students Who Bully}

Strengthening genuine motivation to change. The MI approach, which is predicated first on listening to a young person's own reasons for their bullying behavior, and second on seleetively strengthening the reasons for change that are expressed by the young person, has the potential to be a useful approach when working one-on-one with bullying perpetrators in school settings. Its individualized approach may be particularly useful in light of the complexities of motive discussed above. MI is particularly effective in situations where the client is ambivalent or unaware of the need for change. It can assist the practitioner in listening to and supporting the young person as they explore their own reasons for engaging in the behavior, and evoking from the youth reasons why they might want to do things differently. Motivational interviewing originated "in efforts to find constructive ways of 
responding to clients who were described as resistant, angry, defensive, and "in denial" (Naar-King \& Suarez, 2011, p. xii, p. xii). Adolescents and young adults express these

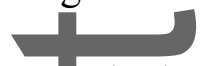

qualities routinely. Youth involved in bullying are likely to be especially resistant and reluctant to genuinely engage in discussions of change, and therefore MI may be especially valuable as a first approach to bullying.

Supporting and encouraging autonomy. In respecting the need for autonomy of the student, MI also has potential to be an acceptable and useful approach for working with young people who bully. Due to the tenets of its "spirit", practitioners aim to work with young people in a way that supports their autonomy, results in genuine collaboration with the youth, and avoids providing the arguments for change or telling the young person what they should do-This is particularly important as achieving autonomy is a key developmental task of adolescence. In the teenage years, youth seek to establish emotional and behavior autonomy, in particular from their parents (Rice \& Dolgin, 2008). They seek opportunities to make decisions on their own about their own lives, and to seek advice when and how they need it from adults. Research on parenting suggests that overt efforts to control the behavior of children and youth may be counterproductive. An over-controlling parenting style is a distinct risk factor for serious aggression problems in children (e.g. Joussemet et al., 2008). Research from parenting further suggests that over-reliance on control as a socialization technique may, furthermore, be counterproductive to engaging the child, since children's response to control is to avoid the parent (Chapman \& Zahn-Waxler, 1982). Coercive control, it would seem, is a recipe for adolescent disengagement. Similarly, a school's approach to reducing bullying when using reactive methods could have the same unintended consequences.

As Roth, Kanat-Maymon, and Bibi (2011) have noted, many anti-bullying programs are unconcerned with supporting the autonomy of those who bully, and focus instead on 
pressuring the perpetrator to change via praise, sanctions, and other extrinsic motivators.

Students who engage in bullying are more likely to report an externalized sense of regulation, rather than identified or otherwise intrinsic 'ownership' of considerateness; whereas students who reported an internalized sense of considerateness were less likely to bully others (Roth \& Bibi, 2009). The classroom experiences of students are a likely setting for these connections to be made: students who perceive their teachers to be autonomy-supportive are less likely to engage in bullying (Roth et al., 2011).

These extrinsic modes of control may succeed in managing behaviors in a classroom setting, but are unlikely to produce lasting or comprehensive change in motivation or behavior. Further, students may become motivated to carry out bullying behavior more covertly to reduee the likelihood of detection. This is supported by self-Determination Theory (SDT), which predicts that adult control by itself is not conducive to changing young people's behavior. According to this theory, behavior regulation via external control rarely translates into long-term internalization of the desired behavior (Ryan \& Connell, 1989). To achieve meaningful self-regulation, according to SDT, the behavior needs to become internalized via the person identifying the value of the behavior for her/himself, and eventually integrating the behavior into their own sense of self.

For youth who bully other students, supporting autonomy requires engaging in a meaningful collaboration. Collaboration -- developing a partnership between the practitioner and the young person - is a key aspect of MI. This collaboration helps the practitioner work from the basis of the challenge the young person faces: how to both realize autonomy and yet negotiate the pressures placed upon him/her by figures of authority to improve their behavior (Naar-King \& Suarez, 2011).

Collaboration is the antithesis of coercion, but should not be mistaken for a permissive approach of moral relativism. Motivational interviewing diverges from strictly 
client-centered therapeutic approaches in emphasizing the necessity of clear direction in relation to a target problem behavior. The mode of focus is one of guiding, not leading, the young person down the road to behavior change. This is achieved through evocation.

Evoking diserepancies between motivations and outcomes. The MI practitioner seeks to evoke discrepancies between the young person's current behavior and their greater goals and yalues. In the case of bullying, this requires an exploration of the social goals and emotional needs that might be fueling the bullying behavior. Rigby (2014) has recently quoted Kierkegaard (1973, p. 333), who wrote that "In order to help another effectively I must understand more than he - yet first of all surely I must understand what he understands". Although each incident of bullying is distinct, research into the perceived motives and social goals of youth who bully has suggested several common patterns.

With most bullying perpetrators, there is likely to be some ambivalence about their behavior, however deeply guarded. Burns, Maycock, Cross, and Brown (2008b) have noted that cognitive dissonance can be detected in student's accounts of their own bullying behaviors. These moments of disconnect -where young people recognize that what they did was wrong, but work nevertheless to find a justification for their behavior-provide footholds that MI practitioners can use to promote motivation to change. The 'bully' label, itself, brings mixed feelings for students (Burns, Maycock, Cross, \& Brown, 2008a). Once a reputation of "being a bully" has been established, it may be difficult to shake the label, which can provide status and power to the young person. The expectations that go along with the label may serve to maintain bullying behaviors (Burns et al., 2008a). But with increasing media attention to the problem of bullying, the label may be increasingly socially toxic to young people, and motivations to stop bullying, even if to simply avoid the label, may be present. The MI practitioner can guide and support the young person to confront the cognitive dissonance between an ugly label and the social prestige it paradoxically brings. Beyond this 
general point of ambivalence, sources of discrepancy will likely be specific to the specific individual motives behind the bullying behavior.

Of these, the notion of bullying as a deliberate striving for extrinsic reward - e.g. lunch money has received the greatest attention from researchers. But more recently, there has been ashift in focus to the gains that can be obtained in the social sphere, in recognition that bullying is often a group phenomenon (Salmivalli, 2010). This shift reflects the move away from conceptualizing bullying as a relationship between two individuals (i.e., the bully and the victim) to one that involves a broader social context (including bystanders, supporters, and defenders), which is both the locus of bullying incidents and the locus of social rewards. When young people consider their experiences of bullying, they reflect on the people-involved, the audience, and their own social position in the peer group; which in part determined what role they decided to take (Salmivalli, 2010). For this reason, the responses of peers, and how these play into the motivation to bully others, has been the focus of bullying prevention strategies such as KiVa (Salmivalli, 2014), and could form a useful part of a MI conversation.

For example, bullying may be a "strategic attempt to gain a powerful position in the peer group" (Reijntjes et al., 2013, p. 1217; see Salmivalli, 2010 for a review of bullying within the peer context). For some children, being seen to be influential may be a greater social goal than feeling close to others (Ojanen, Grönroos, \& Salmivalli, 2005). In early adolescence, in particular, youth who bully may be perceived to be more popular than other children (Cillessen \& Mayeux, 2004; Kiesner \& Pastore, 2005). Peer aggression - at least indirect aggression - even predicts an increased likelihood of having a dating partner, independent of popularity status (Arnocky \& Vaillancourt, 2012). Accordingly, popular students who bully others appear to be less responsive to anti-bullying interventions than those who are less popular (Garandeau, Lee, et al., 2014). Thus, for youth who bully to 
obtain a higher social status, MI can be used to evoke discrepancies between the desired goal - to be popular and influential among peers - and the bullying behavior. The downside of the manner in which bullying affords popularity may become a point of discussion: bullying may achieve popularity in the short term, but this does not mean students who bully others are liked or respected by peers (Sentse, Kiuru, Veenstra, \& Salmivalli, 2014).

Other youth who bully or engage in antisocial behaviors desire to be seen as tough, or 'hard', in the eyes of a select set of antisocial peers (Houghton, Nathan, \& Taylor, 2012). In this context, opportunities for impulsive 'recreational' bullying may become part of the overall reward structure. Many of the recalcitrant bullying youth interviewed in Houghton et al. (2012) refer to the 'fun' involved in maintaining their bad reputation. Recreation and thrill-seeking can be a proximal goal of aggression in general, and have been cited as relevant to violent offending (Bjornebekk \& Howard, 2012a, 2012b), cyber-aggression and cyberbullying (Runions, 2013), and young children's peer aggression (Arsenio, Cooperman, \& Lover, 2000), but are rarely considered in bullying intervention approaches.

Such youth may present a distinct challenge, but here too, MI can non-coercively and non-judgmentally evoke discrepancies between social (and other) goals and current behavior. These may include the desire to avoid extreme negative outcomes (e.g., entanglements with corrective services; continued 'trouble' from the school) that may eventuate in part from the life choices that include ongoing involvement in bullying and antisocial behavior.

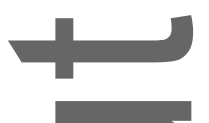

\section{Motivational Interviewing as a Precursor to Further Intervention}

Motivational interviewing is commonly used as a precursor to, or preparation for, other intervention approaches. In fact, the use of MI as a preparation for engagement in subsequent intervention provides the strongest evidence of its efficacy (Lundahl, Kunz, Brownell, Tollefson, \& Burke, 2010). As the joke goes, it takes just one psychologist to 
change a light bulb, but the light bulb has to want to change. No less with bullying: MI may produce the best outcomes when it sets the stage for other reparative or social skill building approaches

In-particular, MI may help prepare the ground for social skills training, among youth who might otherwise resist such learning. Angry students might resent the suggestion that the way they interpret social events is flawed (Gorenstein, Tager, Shapiro, Monk, \& Sloan, 2007; Hawkins \& Cougle, 2013) or believe that it is other students who need to change (Hawkins \& Cougle, 2013). Using MI, the practitioner can enlist the young person's trust and readiness to change, and then engage in further intervention.

For students who engage in bullying for perceived social rewards or reputation enhancement, MI could also be used as a first step toward the method of shared concern. While the method of shared concern aims to 're-humanize' the target of bullying, it may not always be able to promote concern for the target, particularly if there is a perception that the target provoked the incident (Burns et al., 2008b). As the work of Houghton et al. (2012) has made clear, many students who bully are well-aware of the adverse emotional impact of their bullying on their targets. The intent to harm is routinely cited as a fundamental definitional component of both bullying and of aggression more broadly. In such cases, trying to promote concern for the target may be doomed from the start. In this instance, MI can be used to help the young person reframe their own behavior, according to their own values and goals, to reduce the likelihood of continued bullying. Motivational interviewing, we believe, is the only systematic approach available that holds the promise of evoking and realizing such a reframing of one's own motivations in school settings. Integrating Motivational Interviewing in to the School Setting

Unlike clinical settings, school staff members rarely have adequate time to engage one-on-one with students, and Motivational Interviewing is a complex approach that likely 
requires years to master. However, the success of brief MI approaches (Erickson, Gerstle, \& Feldstein, 2005) suggests that its incorporation into school settings may be both feasible and fruitful. However, adapting MI to a school setting is an important consideration, as school staff have little time for therapeutic interventions, and are not generally trained to conduct these. For instance, the nature of bullying may recruit a punitive response in school staff, which is counter to the spirit of MI. The hierarchy of school responses to bullying may also result in tension or conflicting approaches to addressing bullying, which may complicate the implementation of an approach like MI.

We are currently running a cluster-level randomized control trial that aims to examine the efficacy of MI as a school response to bullying perpetration. In our study, schools are randomly assigned to intervention and control conditions. As noted, unlike traditional counselling settings, school staff are time-poor and rarely able to provide intensive psychological support to students. In our trial, we have opted not to train classroom teachers, who have little time to engage in conversations about behaviour change. Instead, we have focused on the staff best positioned to have meaningful conversations about behaviour: school psychologists, deputy principals and other school services or pastoral care staff. In inviting deputy principals, we also aimed to facilitate an understanding of the spirit of MI in working with students who may otherwise be seen primarily through a punitive disciplinary lens.

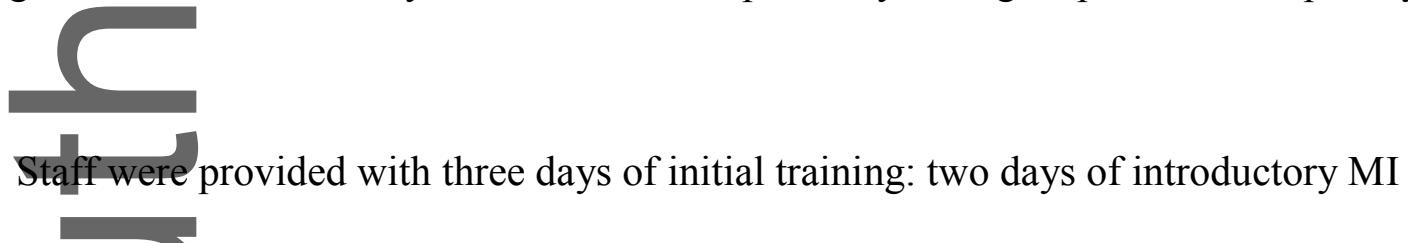
spirit and skills development by a MI Network of Trainers (MINT)-certified trainer, and a third day of professional development about bullying and workshopping of how to apply MI with students who bully. Staff were encouraged to incorporate MI into their work with students, and were able to provide audio-recordings of MI conversations (for consented 
students) to the research team to facilitate ongoing professional development and supervision in MI.

At the end of the initial 3-day training, staff completed the Video Assessment of Simulated-Encounters-Revised (VASE-R; Rosengren, Baer, Hartzler, Dunn \& Wells, 2005; Rosengren, Harzler, Baer,Wells, \& Dunn, 2008). The VASE-R is a training video and assessment toolfor MI skills, and consists of video vignettes of actors portraying clients presenting for substance-abuse problems. We used an adapted version developed in New Zealand in collaboration with Rosengren et al. to address cross-cultural issues from the original (VASE-R-NZ; Matua-Raki, 2012). Coding of responses provides a total score with a suggested cut-off indicating general MI proficiency. Following the preliminary training, fifty staff completed the VASE-R, and 32 (64\%) already scored in the MI proficient range.

We conducted preliminary interviews with those trained staff. The responses to the use of MI with students engaged in bullying or related antisocial behavior was positive. For example, one teacher indicated that “...it's been fantastic in rapport building... We're teachers but we're also mentors, counsellors yet not formally trained." A school psychologist indicated that MI "seems like a viable format of engaging kids in conversation and actuallygetting their perspective on what's happening with their actions."

However, there is evidence that brief approaches to MI can be effective, and schools staff may find the introduction to the spirit of MI alone provides a salutary effect. From our interviews of trained staff, there appears to be a such a recognition that supporting real change amongst troubled students requires more than telling students that they need to change: "sometimes I felt like cutting to the chase and saying, "Hey look, can't you see this?", butyou can't do that. It requires a lot of patience."

These qualitative data indicate that MI is seen by school-based staff as a promising approach, although the potential barriers are clear. It remains to future applied intervention 
research to determine how best to overcome barriers to test whether MI can be efficacious in addressing bullying in schools.

\section{Conclusions}

Change is possible for young people who bully if they are appropriately supported, if their own social motivations for bullying and modes of self-exoneration are heard, listened to, and considered carefully, and if they are treated with the respect with which we want to see them treat others. Motivational interviewing is an established and effective approach for engaging people to make changes in harmful and antisocial behaviors that they may be reluctant to discontinue. For this reason, MI may be effective - alone or used in addition to other intervention strategies - in supporting youth to move beyond bullying to achieve their social goats and emotional needs, and thereby to effect a positive change for all students involved.
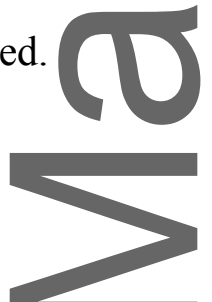

Compliance with Ethical Standards. This manuscript reflects a research study that includes human participants, for which all procedures were conducted in accordance with the ethical standards of the administering university and with the formal review and approval of the [state name redacted for de-identification of manuscript] Department of Education, and with the 1964 Helsinki declaration and its later amendments, as well as the Australian National Health \& Medical Research Council guidelines for ethical human research.

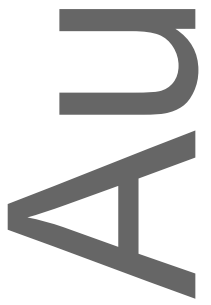

\section{REFERENCES}

Arnocky, S., \& Vaillancourt, T. (2012). A Multi-Informant Longitudinal Study on the Relationship between Aggression, Peer Victimization, and Dating Status in 
Adolescence. Evolutionary Psychology, 10(2), 253-270. Retrieved from $<$ Go to ISI>://WOS:000306398500007

Arsenio, W.F., Cooperman, S., \& Lover, A. (2000). Affective predictors of preschoolers' aggression and peer acceptance: direct and indirect effects. Developmental Psychology, 36(4), 438.

Atkinson, C., \& Woods, K. (2003). Motivational interviewing strategies for disaffected secondary school students: A case example. Educational Psychology in Practice, $19(1), 49-64$.

Berger, K. S. (2007). Update on bullying at school: Science forgotten? Developmental Review, 27(1), 90-126. doi:10.1016/j.dr.2006.08.002

Bjornebekk, G., \& Howard, R. (2012a). Sub-types of angry aggression in antisocial youth: Relationships with self-reported delinquency and teachers' perceptions of social competence and emotional/behavioural problems. Personality and Individual Differences, 53(3), 312-316. doi:10.1016/j.paid.2012.03.033

Bjornebekk, G., \& Howard, R. (2012b). Validation of a motivation-based typology of angry aggression among antisocial youths in Norway. Behavioral Sciences \& the Law, 30(2), 167-180. doi:10.1002/bsl.2007

Blom-Hoffman, J., \& Rose, G. S. (2007). Applying motivational interviewing to schoolbased consultation: A commentary on "Has consultation achieved its primary prevention potential?," an article by Joseph E. Zins. Journal of Educational and Psychological consultation, 17(2-3), 151-156.

Burns, S., Maycock, B., Cross, D., \& Brown, G. (2008a). The power of peers: Why some students bully others to conform. Qualitative Health Research, 18(12), 1704-1716. 
Burns, S., Maycock, B., Cross, D., \& Brown, G. (2008b). 'Woodpushers are Gay': The Role of Provocation in Bullying. International Journal of Mental Health Promotion, 10(4), 41-51. doi:10.1080/14623730.2008.9721775

Chapman, M., \& Zahn-Waxler, C. (1982). Young children's compliance and noncompliance to parental discipline in a natural setting. International Journal of Behavioral Development, 5(1), 81-94.

Cillessen, A. H., \& Mayeux, L. (2004). From censure to reinforcement: Developmental changes in the association between aggression and social status. Child Development, $75(1), 147-163$.

Cunningham, R. M., Walton, M. A., Goldstein, G., Chermack, S. T., Shope, J. T., Bingham, R., Zimmerman, M.A., \& Blow, F.C (2009). Three-month follow-up of brief computerized and therapist interventions for alcohol and violence among teens. Academic Emergency Medicine, 16, 1193-1207.

Cunningham, R. M., Chermack, S. T., Zimmerman, M. A., Shope, J. T., Bingham, C. R., Blow, F. C., \& Walton, M. A. (2012). Brief motivational interviewing intervention for peer violence and alcohol use in teens: one-year follow-up. Pediatrics, 129(6), 10831090

Delfabbro, P., Winefield, T., Trainor, S., Dollard, M., Anderson, S., Metzer, J., \& Harnmarstrom, A. (2006). Peer and teacher bullying/victimization of South Australian secondary school students: Prevalence and psychosocial profiles. British Journal of Educational Psychology, 76, 71-90. doi:10.1348/000709904×24645

Erickson, S. J., Gerstle, M., \& Feldstein, S. W. (2005). Brief interventions and motivational interviewing with children, adolescents, and their parents in pediatric health care settings - A review. Archives of Pediatrics \& Adolescent Medicine, 159(12), 11731180. doi:10.1001/archpedi.159.12.1173 
Erickson, S. J., Gerstle, M., \& Feldstein, S. W. (2005). Brief interventions and motivational interviewing with children, adolescents, and their parents in pediatric health care settings: a review. Archives of Pediatrics \& Adolescent Medicine, 159(12), 11731180

Frey, A. J,Cloud, R. N., Lee, J., Small, J. W., Seeley, J. R., Feil, E. G., . . Golly, A. (2011). The promise of motivational interviewing in school mental health. School Mental Health, 3(1), 1-12.

Garandeau, C. F., Lee, I. A., \& Salmivalli, C. (2014). Differential effects of the KiVa antibullying program on popular and unpopular bullies. Journal of Applied Developmental Psychology, 35(1), 44-50.

Garandeau, C. F., Poskiparta, E., \& Salmivalli, C. (2014). Tackling acute cases of school bullying in the KiVa anti-bullying program: A comparison of two approaches. Journal of Abnormal Child Psychology, 42(6), 981-991. doi:10.1007/s10802-014$9861-1$

Garandeau, C. F., Vartio, A., Poskiparta, E., \& Salmivalli, C. (2016). School bullies' intention to change behavior following teacher interventions: Effects of empathy arousal, condemning of bullying, and blaming of the perpetrator. Prevention Science, 17(8), 1034-1043. doi:10.1007/s11121-016-0712-x

Gorenstein, E. E., Tager, F. A., Shapiro, P. A., Monk, C., \& Sloan, R. P. (2007). Cognitivebehavior therapy for reduction of persistent anger. Cognitive and Behavioral Practice, 14(2), 168-184. doi:10.1016/j.cbpra.2006.07.004

Hawkins, K A, \& Cougle, J. R. (2013). Effects of interpretation training on hostile attribution bias and reactivity to interpersonal insult. Behavior Therapy, 44(3), 479488. 
Hemphill, S. A., Kotevski, A., Herrenkohl, T. I., Bond, L., Kim, M. J., Toumbourou, J. W., \& Catalano, R. F. (2011). Longitudinal consequences of adolescent bullying perpetration and victimisation: A study of students in Victoria, Australia. Criminal Behaviour and Mental Health, 21(2), 107-116. doi:10.1002/cbm.802

Herman, K. C., Reinke, W. M., Frey, A., \& Shepard, S. (2013). Motivational interviewing in schools Strategies for engaging parents, teachers, and students: Springer Publishing Company.

Houghton, S. J., Nathan, E., \& Taylor, M. (2012). To bully or not to bully, that is not the question: Western Australian early adolescents' in search of a reputation. Journal of Adolescent Research, 27(4), 498-522.

Joussemet, M., Vitaro, F., Barker, E. D., Côté, S., Nagin, D. S., Zoccolillo, M., \& Tremblay, R. E. (2008). Controlling parenting and physical aggression during elementary school. Child Development, 79(2), 411-425.

Kiesner, J., \& Pastore, M. (2005). Differences in the relations between antisocial behavior and peer acceptance across contexts and across adolescence. Child Development, $76(6), 1278-1293$.

Kim, M. J. Catalano, R. F., Haggerty, K. P., \& Abbott, R. D. (2011). Bullying at elementary school and problem behaviour in young adulthood: A study of bullying, violence and substance use from age 11 to age 21. Criminal Behaviour and Mental Health, 21(2), 136-144. doi: $10.1002 / \mathrm{cbm} .804$

Kistenmacher, B, R., \& Weiss, R. L. (2008). Motivational interviewing as a mechanism for change in men who batter: A randomized controlled trial. Violence and Victims, $23(5), 558-570$. 
Lee, J., Frey, A. J., Herman, K., \& Reinke, W. (2014). Motivational interviewing as a framework to guide school-based coaching. Advances in School Mental Health Promotion, 7(4), 225-239.

Lester, L.,Cross, D., Dooley, J., \& Shaw, T. (2013). Developmental trajectories of adolescent victimization: Predictors and outcomes. Social Influence, 8(2-3), 107-130. doi:10.1080/15534510.2012.734526

Lundahl, B. W., Kunz, C., Brownell, C., Tollefson, D., \& Burke, B. L. (2010). A metaanalysis of motivational interviewing: Twenty-five years of empirical studies. Research on Social Work Practice.

Matua Raki (2012). Video Assessment of Simulated Encounters - Revised - New Zealand. Administration and Scoring Manual. Matua Raki, Wellington, New Zealand.

McNamara, E. (2009). Motivational Interviewing: Theory, practice and applications with children and young people: Dr Edward Mcnamara.

Miller, W. R, \& Rollnick, S. (2012). Motivational interviewing: Helping people change: Guilford press.

Moore, S.E., Norman, R. E., Sly, P. D., Whitehouse, A. J. O., Zubrick, S. R., \& Scott, J. (2014). Adolescent peer aggression and its association with mental health and substance use in an Australian cohort. Journal of Adolescence, 37(1), 11-21. doi:10.1016/j.adolescence.2013.10.006

Musser, P. H., Semiatin, J. N., Taft, C. T., \& Murphy, C. M. (2008). Motivational interviewing as a pregroup intervention for partner-violent men. Violence and Victims, $23(5), 539-557$.

Naar-King, S., \& Suarez, M. (2011). Motivational interviewing with adolescents and young adults: Guilford Press New York: 
Ojanen, T., Grönroos, M., \& Salmivalli, C. (2005). An interpersonal circumplex model of children's social goals: links with peer-reported behavior and sociometric status. Deve Developmental Psychology, 41(5), 699.

Olweus, D. (1993). Victimization by peers: Antecedents and long-term outcomes. Social withdrawal, inhibition, and shyness in childhood, 315, 341.

Reich, C. M., Sharp, K. M. H., \& Berman, J. S. (2015). A motivational interviewing intervention for the classroom. Teaching of Psychology, 0098628315603250.

Reijntjes, A., Vermande, M., Olthof, T., Goossens, F. A., Van De Schoot, R., Aleva, L., \& Van Der Meulen, M. (2013). Costs and benefits of bullying in the context of the peer group: A three wave longitudinal analysis. Journal of Abnormal Child Psychology, $41(8), 1217-1229$.

Rice, F. P., \& Dolgin, K. G. (2008). The adolescent: Development, relationships, and culture: Allyn \& Bacon.

Rigby, K. (2014). How teachers address cases of bullying in schools: a comparison of five reactive approaches. Educational Psychology in Practice, 30(4), 409-419. doi: $10.1080 / 02667363.2014 .949629$

Roland, E. (2002). Bullying, depressive symptoms and suicidal thoughts. Educational Research, 44(1), 55-67. doi:10.1080/00131880110107351

Rosengren DB, Baer JS, Hartzler B, Dunn CW, \& Wells EA. The Video Assessment of Simulated Encounters (VASE): Development and validation of a group-administered method for evaluating clinician skills in motivational interviewing. Drug and Alcohol Dependence 79(3): 321-330, 2005.

Rosengren DB, Hartzler B, Baer JS, Wells EA, Dunn CW. The Video Assessment of Simulated Encounters - Revised (VASE-R): Reliability and validity data of a revised 
measure for motivational interviewing skills. Drug Alcohol Depend 2008;97:130138.

Roth, G., Kanat-Maymon, Y., \& Bibi, U. (2011). Prevention of school bullying: The important role of autonomy-supportive teaching and internalization of pro-social values. British Journal of Educational Psychology, 81(4), 654-666.

Runions, K. C. (2013). Toward a conceptual model of motive and self-control in cyberaggression: Rage, revenge, reward, and recreation. Journal of youth and adolescence, $42(5), 751-771$.

Ryan, R. M., \& Connell, J. P. (1989). Perceived locus of causality and internalization: examining reasons for acting in two domains. Journal of personality and social psychology, 57(5), 749.

Salmivalli, C. (2010). Bullying and the peer group: A review. Aggression and violent behavior, 15(2), 112-120.

Salmivalli, C. (2014). Participant Roles in Bullying: How Can Peer Bystanders Be Utilized in Interventions? Theory into Practice, 53(4), 286-292. doi: $10.1080 / 00405841.2014 .947222$

Sentse, M, Kiuru, N., Veenstra, R., \& Salmivalli, C. (2014). A Social Network Approach to the Interplay Between Adolescents' Bullying and Likeability over Time. Journal of Youth and Adolescence, 43(9), 1409-1420. doi:10.1007/s10964-014-0129-4

Sheftel, A., Lindstrom, L., \& McWhirter, B. (2014). Motivational enhancement career intervention for youth with disabilities. Advances in School Mental Health Promotion, 7(4), 208-224.

Smith, J. D., Schneider, B. H., Smith, P. K., \& Ananiadou, K. (2004). The effectiveness of whole-school antibullying programs: A synthesis of evaluation research. School psychology review, 33(4), 547. 
Strait, G. G., McQuillin, S., Smith, B., \& Englund, J. A. (2012). Using motivational interviewing with children and adolescents: A cognitive and neurodevelopmental perspective. Advances in School Mental Health Promotion, 5(4), 290-304. dot: $10.1080 / 1754730 X .2012 .736789$

Strait, G. G., McQuillin, S., Terry, J., \& Smith, B. H. (2014). School-based motivational interyiewing with students, teachers, and parents: new developments and future direction. Advances in School Mental Health Promotion, 7(4), 205-207.

Strait, G. G., Smith, B. H., McQuillin, S., Terry, J., Swan, S., \& Malone, P. S. (2012). A randomized trial of motivational interviewing to improve middle school students' academic performance. Journal of Community Psychology, 40(8), 1032-1039.

Terry, J., Strait, G., McQuillin, S., \& Smith, B. H. (2014). Dosage effects of motivational interviewing on middle-school students' academic performance: randomized evaluation of one versus two sessions. Advances in School Mental Health Promotion, $7(1), 62-74$.

Thompson, F., \& Smith, P. K. (2012). Anti-bullying strategies in schools: what is done and what works. British Journal of Educational Psychology, 2(9), 154-173.

Ttofi, M. M., \& Farrington, D. P. (2011). Effectiveness of school-based programs to reduce bullying. A systematic and meta-analytic review. Journal of Experimental Criminology, 7(1), 27-56.

Ttofi, M. M., Farrington, D. P., Loesel, F., \& Loeber, R. (2011). The predictive efficiency of school bullying versus later offending: A systematic/meta-analytic review of longitudinal studies. Criminal Behaviour and Mental Health, 21(2), 80-89. doi: $10.1002 / \mathrm{cbm} .808$

Ttofi, M. M., Farrington, D. P., Lösel, F., Özdemir, M., \& Stattin, H. (2011). Bullies, victims, and bully-victims: a longitudinal examination of the effects of bullying-victimization 
experiences on youth well-being. Journal of Aggression, Conflict and Peace Research, 3(2), 97-102.

Van Geel, M., Vedder, P., \& Tanilon, J. (2014). Relationship between peer victimization, cyberbutlying, and suicide in children and adolescents A meta-analysis. Jama Pediatrics, 168(5), 435-442. doi:10.1001/jamapediatrics.2013.4143

Werth, J. M., Nickerson, A. B., Aloe, A. M., \& Swearer, S. M. (2015). Bullying victimization and the social and emotional maladjustment of bystanders: a propensity score analysis. Journal of school psychology, 53(4), 295-308.

Woodin, E. M., \& O’Leary, K. D. (2010). A brief motivational intervention for physically aggressive dating couples. Prevention Science, 11(4), 371-383.

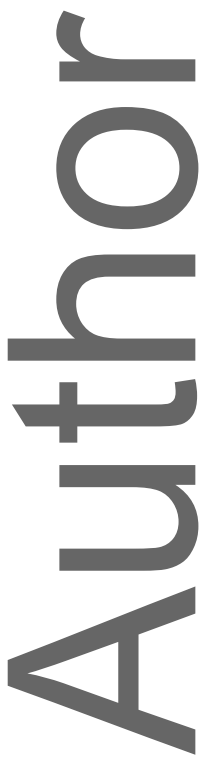

